\title{
Exploring the Use of Video-Recorded Practical Examination Performance to Enhance Student Self-Assessment
}

\author{
Ellen R. Perlow \\ Mercer University, perlow_er@mercer.edu \\ Niamh M. Tunney \\ Mercer University, tunney_nm@mercer.edu \\ Jeffrey G. Ebert \\ Mercer University, ebert_jg@mercer.edu
}

Follow this and additional works at: https://nsuworks.nova.edu/ijahsp

Part of the Physical Therapy Commons

This Manuscript has supplementary content. View the full record on NSUWorks here: https://nsuworks.nova.edu/ijahsp/vol17/iss4/12

\section{Recommended Citation}

Perlow ER, Tunney NM, Ebert JG. Exploring the Use of Video-Recorded Practical Examination Performance to Enhance Student Self-Assessment. The Internet Journal of Allied Health Sciences and Practice. 2019 Jan 01;17(4), Article 12.

This Manuscript is brought to you for free and open access by the College of Health Care Sciences at NSUWorks. It has been accepted for inclusion in Internet Journal of Allied Health Sciences and Practice by an authorized editor of NSUWorks. For more information, please contact nsuworks@nova.edu. 


\title{
Exploring the Use of Video-Recorded Practical Examination Performance to Enhance Student Self-Assessment
}

\begin{abstract}
ABSTRACT

Purpose: The purposes of this study were to explore the ability of doctor of physical therapy students to self-assess performance during a video-recorded practical examination, to evaluate student perceptions of the experience, and to determine their perception of their ability to self-assess. Method: A cross-sectional design with students from 2 consecutive cohorts was utilized. Participants worked in groups of three conducting a video-recorded gait training session. Students graded their own performance immediately upon completing the practical examination. Students then regraded their performance from the video recording. The instructor graded each student's video-recorded performance using the same rubric as the students. Following the experience, students completed a 7-question survey administered via Survey Monkey. Data were analyzed using Friedman's ANOVA with post-hoc Wilcoxon signed-rank test to compare median scores. Cohen's Kappa and percent agreement calculations assessed inter- and intra-rater reliability. Student perception data were analyzed using descriptive statistics and non-parametric Wilcoxon signed-rank test. Results: The only significant difference in scores was between student-live and faculty examiner assessments for Cohort 2. Inter-rater reliability (.09-.17) and percent agreement (20.7\%-26.3\%) were low across all comparisons. Intra-rater reliability (.12-.23) and percent agreement (23.7\%-34.5\%) were also low for both cohorts. Students rated their ability to self-assess from the video-recorded performance significantly higher than from the live performance (pConclusions:Students' ability to self-assess performance does not appear to be well developed in the early stages of physical therapy education. The use of video-recorded performance, in conjunction with instructor feedback, could enhance this ability, ideally leading to independent and effective self-assessment as students proceed through the curriculum.
\end{abstract}

\section{Author Bio(s)}

Ellen R. Perlow, PT, DPT, is a clinical assistant professor in the Department of Physical Therapy at Mercer University in Atlanta, Georgia. She is also a licensed physical therapist in the state of Georgia.

Niamh M. Tunney, PT, DPT, MS, is a clinical associate professor in the Department of Physical Therapy at Mercer University in Atlanta, Georgia. She is also a licensed physical therapist in the state of Georgia.

Jeffrey G. Ebert, PT, DPT, OCS, is a clinical assistant professor in the Department of Physical Therapy at Mercer University in Atlanta, Georgia. He is also a licensed physical therapist in the state of Georgia.

\section{Acknowledgements}

We would like to acknowledge the assistance of Dr. Alyssa Laforme Fiss, PT, PhD, PCS, with her assistance with statistical analysis. 


\title{
IIIAHSP
}

\section{The Internet Joutnal of Allied Health Sciences and Practice \\ Dedicated to allied health professional practice and education}

Vol. 17 No. 4 ISSN 1540-580X

\section{Exploring the use of Video-recorded Practical Examination Performance to Enhance Student Self-assessment}

\author{
Ellen R. Perlow \\ Niamh M. Tunney \\ Jeffrey G. Ebert \\ Mercer University \\ United States
}

\begin{abstract}
Purpose: The purposes of this study were to explore the ability of doctor of physical therapy students to self-assess performance during a video-recorded practical examination, to evaluate student perceptions of the experience, and to determine their perception of their ability to self-assess. Method: A cross-sectional design with students from 2 consecutive cohorts was utilized. Participants worked in groups of three conducting a video-recorded gait training session. Students graded their own performance immediately upon completing the practical examination. Students then regraded their performance from the video recording. The instructor graded each student's video-recorded performance using the same rubric as the students. Following the experience, students completed a 7-question survey administered via Survey Monkey. Data were analyzed using Friedman's ANOVA with post-hoc Wilcoxon signed-rank test to compare median scores. Cohen's Kappa and percent agreement calculations assessed inter- and intra-rater reliability. Student perception data were analyzed using descriptive statistics and non-parametric Wilcoxon signed-rank test. Results: The only significant difference in scores was between student-live and faculty examiner assessments for Cohort 2. Inter-rater reliability (.09-.17) and percent agreement (20.7\%-26.3\%) were low across all comparisons. Intra-rater reliability (.12.23) and percent agreement (23.7\%-34.5\%) were also low for both cohorts. Students rated their ability to self-assess from the video-recorded performance significantly higher than from the live performance $(p<.001)$. For both cohorts, the perceived stress from the video-recorded performance was significantly less than the perceived stress of a live performance $(p<.001)$. Conclusions: Students' ability to self-assess performance does not appear to be well developed in the early stages of physical therapy education. The use of video-recorded performance, in conjunction with instructor feedback, could enhance this ability, ideally leading to independent and effective self-assessment as students proceed through the curriculum.
\end{abstract}

Keywords: self-assessment, video recording, practical examination, anxiety 


\section{INTRODUCTION}

\section{Background and Purpose}

Assessment of clinical skills is an important component of student assessment in physical therapy (PT) curricula.1,2 This assessment is commonly conducted using practical examinations. Practical examinations differ from traditional examinations in that students are asked to "perform, create, or produce something significant that is related to both previous instructional activities and real-world applications." 3 They assess student communication, psychomotor skills, and safety required for the execution of physical therapy procedures with future patients. ${ }^{4}$ They can help faculty predict student capability on clinical internships and in future practice more accurately than traditional written examinations used in the didactic curriculum. ${ }^{5}$

In addition to allowing faculty assessment of student performance, practical examinations also provide an opportunity for students to self-assess, or rate, their own ability to communicate and perform newly learned PT skills. Vendrely proposed that the objective of practical examinations is to develop skills and characteristics necessary for reflective practice. ${ }^{3}$ Reflective practice links theory and practice as the clinician consciously thinks through the clinical experience with the goal of improving performance. ${ }^{6,7}$ Reflective practice learning activities afford students the opportunity to consciously reflect on their own behaviors to become both active and adult learners, to notice improvements in professional practice, and to gain confidence in their self-assessment skills to become self-regulated learners. ${ }^{8-12}$ Self-assessment and self-regulated learning, which is the ability to adapt behavior based on that selfassessment, are both required for developing expert skills and lifelong learning; educators have struggled with how to teach these crucial skills effectively. ${ }^{9-11,13-15}$

The APTA Guide for Professional Conduct describes self-assessment as "a lifelong professional responsibility for maintaining professional competence."16 Previous studies in health care education have shown that reflective practice encourages improvements in communication and clinical skills, which are essential in successful physical therapy practice.8,9,17,18 Students' inability to assess their own skills will limit professional growth and may also potentially compromise patient safety. ${ }^{13}$ It has been a challenge and a goal for many professional programs, including physical therapy, nursing, pharmacy, and medicine, to provide learning and assessment experiences to develop students' clinical competence and evolution into self-regulated learners., $2,9-14,17,19$ Additionally, in healthcare professional programs, the ability to self-assess has been identified as being more challenging earlier in the program and does not improve considerably throughout the didactic education. ${ }^{12}$ Research also suggests that students who perform lower academically tend to overestimate their performance, while students who perform higher academically tend to underestimate their performance. ${ }^{12,13,17,20}$ Furthermore, male students tend to overestimate their performance more than female students. ${ }^{17,21}$

Video-recording has been used as a self-assessment tool in several health care professional programs., $.10,22-24$ Video recordings provide students with an opportunity to "directly witness their own performance" and critically examine their interactions and interventions with patients, allowing them to become more responsible for their own learning. ${ }^{8,10}$ The literature has supported video recording as an effective tool to improve student history-taking and psychomotor skills competence. ${ }^{18,25}$ There is debate, however, whether video-recorded student assessments improve student self-reflective capabilities.10,13,18,26

In order to be effective as a self-assessment experience, it is important that students can assess their performance in a manner comparable to the instructor, and a practical examination provides that opportunity. 8,10 Therefore, this study examines the use of a video-recorded practical examination to explore the ability of first-year doctor of physical therapy (DPT) students to self-assess performance. The purposes of this study are: 1) to compare student self-assessment scores immediately after completing the practical examination and after reviewing a video recording of their performance; 2 ) to compare student scores from both conditions to faculty scores from the video recordings; 3 ) to determine student perceptions of their ability to self-assess their performance; and 4) to gauge student perceptions of the experience.

\section{METHODS \\ Design}

A cross-sectional design was utilized for this study. Approval was received from the University's Institutional Review Board. All students were required to undergo assessment of their clinical skills, and those agreeing to participate in the study gave informed consent to use their data and complete the perception survey.

\section{Sample and Setting}

Participants included students from two consecutive cohorts of a DPT program. Students in the second semester of an eightsemester DPT program participated in an assistive device gait training practical examination as a course requirement. A cohort of 
29 DPT students (19 females and 10 males) and 2 faculty members participated in 2017 (Cohort 1), and a second cohort of 38 DPT students (25 females and 13 males) and the same 2 faculty members participated in 2018 (Cohort 2). (Table 1)

Table 1. Student Demographics

\begin{tabular}{|l|l|l|l|}
\hline DPT Students & Sample size & Sex $(\%)$ & Mean age in years/ (SD) \\
\hline Cohort 1 2017 & 29 & $\begin{array}{l}10 \text { males }(34.5 \%) \\
19 \text { females }(65.5 \%)\end{array}$ & $22.47 /(3.18)$ \\
\hline Cohort 2 2018 & 38 & $\begin{array}{l}13 \text { males }(34.2 \%) \\
25 \text { females }(65.8 \%)\end{array}$ & $22.53 /(2.26)$ \\
& & & \\
\hline
\end{tabular}

\section{Materials and Instruments}

A grading rubric was developed by the course instructor to measure performance on a 39-point scale. (Appendix A) The gait training rubric was divided into 4 primary areas: communication, demonstration, fitting for an assistive device, and gait training. Each primary area had multiple sub-categories, each of which was scored on a dichotomous scale.

\section{Procedures}

The practical examination was conducted using video-recorded performance. Use of video recording allowed the students to complete the practical examination without direct faculty supervision. Video recording was achieved by randomly dividing students into groups of three. Within each group, students played each of the following roles in rotation: student physical therapist (SPT), standardized patient, and videographer. The order of rotation through these roles was randomly assigned by the course instructor. This rotation required three different patient scenarios for each group as each student within a group, in turn, assumed the role of the SPT. Patient scenarios were randomly assigned to the students in each group.

Prior to the start of the examination, all students were provided with a set of detailed instructions, and all were instructed to wear professional attire. Only the student actively portraying the SPT role was to wear a white lab coat and name badge, which clearly differentiated him/her as the SPT. Students were prohibited from practicing the scenario immediately prior to the performance. This was achieved by limiting performance time for each group to 12 minutes per student and imposing point deductions for going over the time limit. Additionally, a faculty member was walking within view of the examination areas and monitoring the activity from outside of the rooms. The faculty patrolled the hallways to ensure that the students adhered to the instructions and times allotted. Faculty did not attend to the actual performances by the students. No communication about the session or feedback from the videographer or standardized patient was allowed during the video session. Each group had a total of one hour reserved in one of the classrooms, allowing each student time to complete the gait training skill and time to switch roles within the group. The students were given this logistical information on their learning management system one week prior to the practical examination date.

All three students within a group, at their designated time for the practical examination, simultaneously picked up their assigned patient scenarios for their role as the SPT from the course instructor. They were given ten minutes to read the scenario in preparation for their performance. The SPT shared the patient scenario with the standardized patient and verbalized any special instructions immediately prior to the acting performance. The patient scenarios were uncomplicated to facilitate ease of acting as a standardized patient. The patient cases included possible restricted weight-bearing status, lower extremity weakness, extremity pain, or mild balance deficits. There were nine possible patient scenarios to which a student could be assigned. Students had practiced role-playing similar patient scenarios in class, which helped negate the need for processing and practice time during the practical examination session.

Each classroom used for the practical examination was equipped with two wheelchairs (one for the standardized patient, and one for the SPT to use for demonstration) and assistive devices for all possible patient scenarios. All standardized patients were sitting in a wheelchair with footrests at the start of the session and were returned to this position by the end of the examination. The students were responsible for bringing their own gait belts, recording devices, computers, and headphones. Several departmentowned devices were available for use if the student did not have access to a device. Because of recording issues with their own devices, three students used the department's devices in 2017, and one student used the department's device in 2018.

Immediately after all group members had completed the video practical examination, the students proceeded to a designated room to complete a self-assessment rubric on Survey Monkey based solely on their memory of their performance. Following completion of the self-assessment rubric, each student uploaded his/her video to a private course YouTube page. The second faculty member was present in this room to supervise students throughout this process and to provide technical assistance where needed. After the students uploaded their videos, they watched the video using headphones to avoid disturbing the other students in the room. 
They then completed the self-assessment rubric on Survey Monkey based on what they observed in their video recording. Lastly, students completed a perception survey regarding their experience with this practical examination. This survey used a Likert Scale and was administered on Survey Monkey (Appendix B).

For consistency, a single faculty examiner watched all student video performances for both cohorts in 2017 and 2018 and used the same grading rubric as the students. This faculty examiner was the course instructor who taught the course, developed expectations for performance on the practical examination, and designed the self-assessment rubric. Expectations for performance and the self-assessment rubric were reviewed and approved by the clinical faculty and curriculum committee chair.

\section{DATA ANALYSIS}

Data were analyzed using SPSS Version 21. Descriptive statistics were completed for student demographics (Table 1). Friedman's ANOVA with post hoc Wilcoxon were completed to compare the median scores for each cohort from the student-live (condition 1), student-recorded (condition 2), and faculty examiner (condition 3) assessments. Cohen's Kappa and percent agreement calculations were used to assess the relationships between the three conditions. Student perception data were analyzed using descriptive statistics and non-parametric Wilcoxon Signed Rank Test. The priori for this study was set at $p<0.05$.

\section{RESULTS}

There was no significant difference in median scores between student-live and student-recorded self-assessments for either Cohort (Table 2). For Cohort 1 , the intra-rater reliability for scores between student-live to student-recorded conditions was 0.23 , and the percent agreement was $34.5 \%$. For Cohort 2, the intra-rater reliability for scores between student-live to student-recorded conditions was 0.12 , and the percent agreement was $23.7 \%$ (Table 3 ).

Median practical examination scores for the student-live to faculty examiner and student-recorded to faculty examiner conditions were compared. For Cohort 1, no significant differences in median scores were noted between student-live to faculty examiner and student-recorded to faculty examiner (Table 2). For Cohort 2, there was no significant difference for median scores between student-recorded and faculty examiner assessments. A significant difference was noted in median scores between the studentlive and faculty examiner conditions ( $p=.01$ ) for Cohort 2 (Table 2 ).

For Cohort 1 , the interrater reliability was 0.10 between scores for the student-live and faculty examiner conditions and was 0.09 between scores for the student-recorded and faculty examiner conditions. Percent agreement of scores was $20.7 \%$ for both the student-live to faculty examiner conditions and the student-recorded to faculty examiner conditions. For Cohort 2, interrater reliability was 0.10 between scores for the student-live to faculty examiner conditions, and 0.17 between scores for the studentrecorded to faculty examiner conditions. Percent agreement of scores was $21.0 \%$ and $26.3 \%$, respectively, for the student-live to faculty examiner conditions and the student-recorded to faculty examiner conditions (Table 3 ).

Table 2. Comparison of Medians between Student and Faculty

\begin{tabular}{|lcrrrrc|}
\hline Assessment & Median scores (SD) & Range & $\begin{array}{l}\text { Chi } \\
\text { Square }\end{array}$ & p-value & Pairwise Comparison & p-value \\
COHORT 1 & & & .62 & .73 & & \\
Student-live & $36.0(2.4)$ & $29-39$ & & & & \\
Student-recorded & $36.0(2.6)$ & $27-38$ & & & & \\
Faculty & $35.0(2.2)$ & $29-39$ & & & & \\
COHORT 2 & & & 8.5 & .02 & & \\
Student-live & $36.0(2.1)$ & $30-39$ & & & Student-recorded & .13 \\
& & & & & Faculty & $.005^{*}$ \\
Student-recorded & $35.0(2.2)$ & $30-39$ & & & Faculty & .08 \\
Faculty & $34.5(2.4)$ & $29-39$ & & & \\
\hline
\end{tabular}

(C) The Internet Journal of Allied Health Sciences and Practice, 2019 
Table 3. Intra-rater and Inter-rater Reliability across Conditions

\begin{tabular}{|llcc|}
\hline Assessment & Comparison Assessment & Percent Agreement & Cohen's Kappa \\
Student-live & & & .23 \\
& Student recorded & $34.5 \%$ & .10 \\
Student-recorded & Faculty & $20.7 \%$ & .09 \\
COHORT 2 & Faculty & $20.7 \%$ & .12 \\
Student-live & & & .10 \\
& Student recorded & $23.7 \%$ & .17 \\
Student-recorded & Faculty & $21.0 \%$ & $26.3 \%$ \\
\hline
\end{tabular}

The findings from questions 3 and 4 on the perception survey (Appendix B) indicate that students felt they were better able to selfassess performance from the video-recording (Figure 1). When rating their ability to accurately assess their performance after the live examination, the median response of students from both Cohort 1 and Cohort 2 was 7 (range 3-10) where 0 indicates no ability and 10 indicates perfect ability. The median response of students from Cohort 1 when rating their ability to self-assess after watching the video examination was 9 (range 5-10) and from Cohort 2 was 9 (range 7-10). Students rated their perceived ability to self-assess from the video-recorded performance significantly higher than from the live performance ( $p<.001$ for both cohorts).

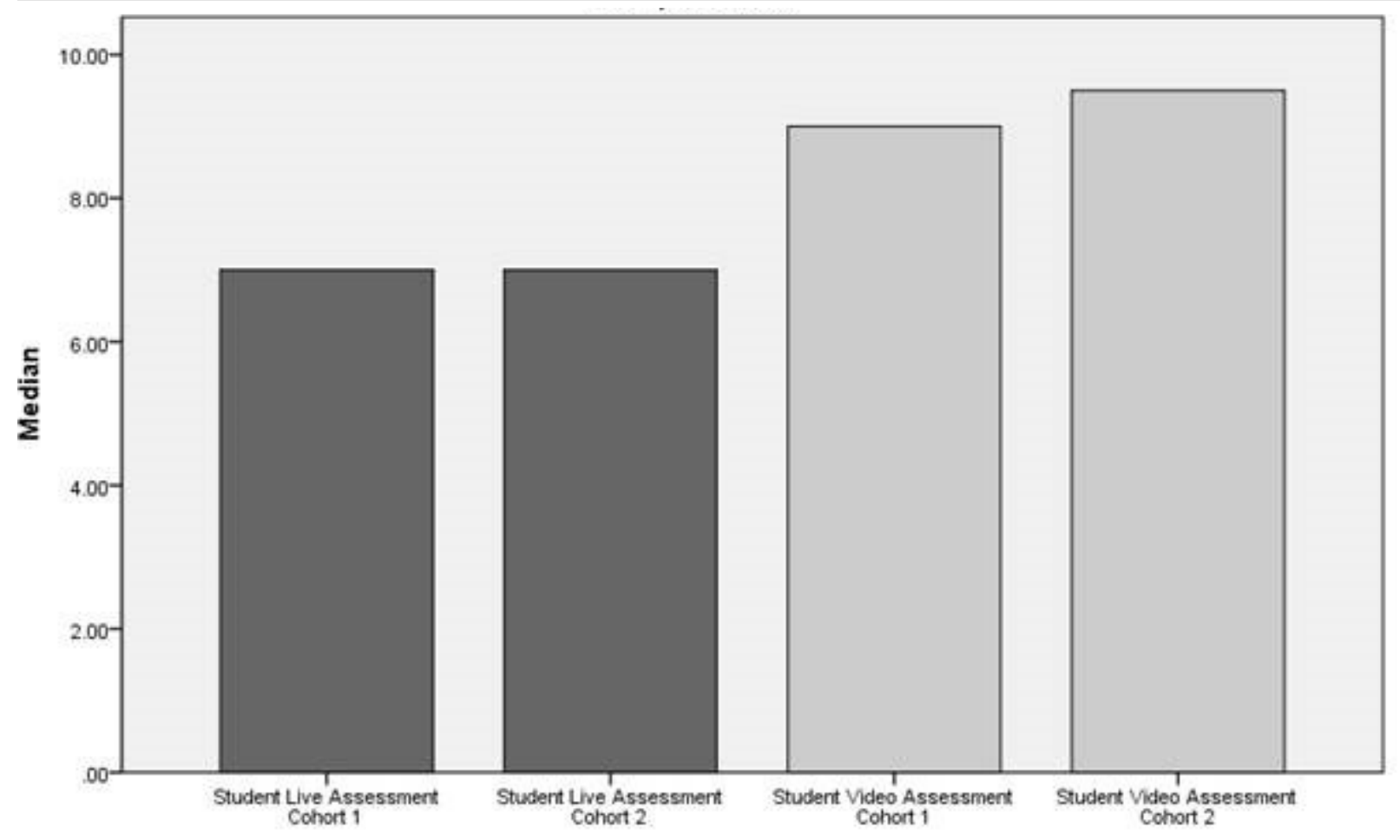

Figure 1. Comparison of Student Perceived Ability to Self-Assess during Live vs. Video-Recorded Competencies

The median stress levels reported by both Cohort 1 and Cohort 2 when reflecting about a more traditional practical examination assessing patient transfer skills that was conducted earlier in the same semester and within the same course was 7 (range 1-10 for Cohort 1 and 2-10 for Cohort 2). For that examination, the faculty member acted as both the standardized patient and the grader for each student. After the video-recorded gait practical examination, the median stress level reported by Cohort 1 was 4 (range 1-8) and for Cohort 2 was 3 (range 1-7). For both cohorts, the perceived stress from a video-recorded performance was significantly less than the perceived stress of a live performance $(p<.001)$ (Figure 2$)$. When asked if they would like to have more testing experiences using this format, 92\% from Cohort 1 and $89 \%$ from Cohort 2 responded affirmatively. 


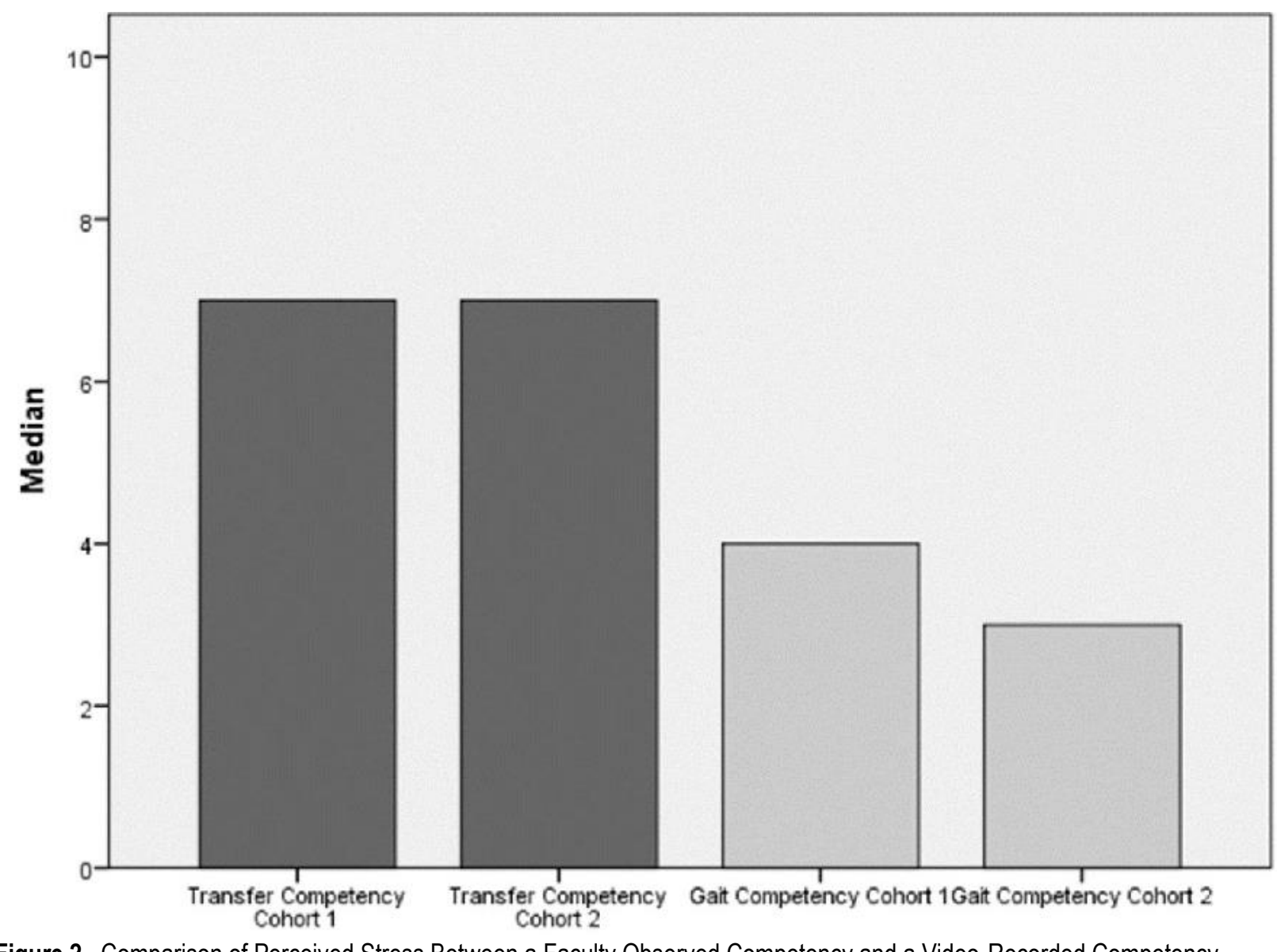

Figure 2. Comparison of Perceived Stress Between a Faculty Observed Competency and a Video-Recorded Competency

Questions 5 and 6 of the perception survey use a 0-10 agreement scale to ask the students whether they felt they could identify areas of strength and weakness that they did not recognize prior to the video recording. For their perceived ability to recognize their strengths after reviewing their recorded performance, the students' median level of agreement was 7.5 (range 0-10) and 8 (range 2-10) for Cohort 1 and Cohort 2, respectively. For their perceived ability to recognize their weaknesses after reviewing their recorded performance, the students' median level of agreement was 9 (range 2-10) and 10 (range 5-10) for Cohort 1 and Cohort 2, respectively.

\section{DISCUSSION}

This study aimed to explore whether practical examinations using a video-recorded format enhanced student self-reflection. Results of this study found low reliability and low percent agreement between scores assigned by the students and scores assigned by the faculty examiner for both live and video-recorded self-assessments. Additionally, findings indicate that students did score themselves differently on the video-recorded performance and the live performance, but there was no consistent pattern in the differences between the scores. Some students scored themselves more critically after observing the video while others were more critical immediately following the live performance. The low intra-rater reliability between scores of the student-live and studentrecorded conditions might indicate that students were adjusting their scores, noticing accuracy or errors on the video recording that they did not perceive after the live performance. However, student scores in the student-live and in the student-recorded conditions were not consistent with the faculty examiner scores. All of these findings indicate that students' ability to self-assess early in their PT education may be lacking, and that video recording their performance did not make a significant difference in their ability to self-assess for the students as a whole.

The low reliability between student-live and student-recorded self-assessment indicates that despite arriving at similar median scores for the assessment, there was a lot of variability in where they assigned the points and how the point assignment changed from live to video-recorded conditions. Previous literature has proposed that higher achieving students can be more critical of their 
performance and lower achieving students may tend to be less critical, which could potentially account for the inconsistency in selfassessment noted in this study.12,13,17,20 For all students, the live condition relies on perception and memory of performance while the video relies on actual performance. The video performance could change their self-assessment in either direction depending on their initial perception.

The finding that PT students have poor ability to self-assess is consistent with findings from similar studies in other healthcare professional programs. ${ }^{10,18,26}$ The poor reliability between the students' and the instructor's assessment of performance, regardless of whether they self-assessed immediately or from the video-recording, indicates that students at this stage of their education still require faculty assessment and feedback. This finding is in agreement with previous studies that report faculty feedback continues to be important in the early stages of skill acquisition. ${ }^{13}$ If the student has not learned the psychomotor skill appropriately, then that student's ability to self-assess will be limited. This is supported by Langendyk who stated that weaker students are less likely to be able to accurately measure their own weaknesses. ${ }^{20}$ However, it is important that students learn to self-assess to be effective healthcare professionals. Even if their ability to do so at this point in their education is limited, video recording performance during the assessment of clinical skills could be a step toward developing this important skill, provided that faculty feedback is also given as a component of the assessment process. Having access to a recording of their performance would allow the student to compare their self-assessment to the faculty assessment to gain further insight. In addition, performing the self-assessment in the context of a practical examination lends itself to student investment in the process, particularly knowing that their assessment will be compared to the faculty assessment.

While the students' perception of their ability to self-assess from a video recording was better than from the live performance, the reality was that they were not able to accurately assess from either method when compared to the faculty examiner. The students' positive perception could simply be a function of their preconception that they would be better able to score themselves from the video recording. Alternatively, perception data from the survey indicates that students felt able to identify areas of strengths and weaknesses from the video recording that they had not previously recognized. This finding could relate to factors they recognized that were not included on this rubric such as professional behaviors as well as verbal and nonverbal communication. Although they were unable to accurately score their own performance from the rubric, they were able to visualize their own strengths and weakness on a much broader level, indicating that all aspects of performance cannot be captured using this rubric. This finding indicates that there may be additional value to utilizing video-recorded performance as a tool to enhance self-reflection beyond grading which is supported in the literature. ${ }^{10}$

An interesting outcome from the perception survey relates to the issue of student stress during practical examinations. The format of this practical examination seemed to produce less stress than traditional formats in which the faculty is present and grading the live performance as it occurs. Practical examinations have been identified as highly stressful in nursing, dental, and PT education programs. ${ }^{3,23,24}$ The process of the practical examination and uncertainty about the case and environment appear to increase anxiety and a fear of failing. ${ }^{27}$ Students in health professions report that traditional practical examinations make them very anxious. ${ }^{28}$ Medical students indicated that practical examinations made them more anxious than any other form of testing. ${ }^{29}$ PT students reported anxiety regarding performance not reflecting their true abilities. ${ }^{23}$ While the video-recorded practical examination retains some of the features of a traditional practical examination, the removal of the direct supervision by faculty could be one factor that reduced the stress. The design of a practical examination should consider the stress levels of students undergoing assessment. This is an important consideration for faculty as PT students have been shown to have higher levels of anxiety and stress than similarly aged peers. ${ }^{30}$

There were some logistical benefits to the format of this practical examination beyond the student experience. One faculty grader potentially resulted in improved grading consistency. Panzarella and Manyon reported that one professor giving a practical examination in isolation versus the entire faculty leads to "greater validation and integration of curricular content." 2 There was no demand on other faculty members' time, as the two course faculty were able to conduct the practical examination within the scheduled class meeting time. Additionally, there was no need to pay outside examiners or standardized patients, and students were able to utilize their own recording devices, all of which eliminated any cost associated with this practical examination.

Challenges presented by this format included the need for sufficient space to allow only one group per room during testing because of the need for a quiet recording environment. There was also a need for quiet space for the students to observe their videos. Another challenge was the time demand placed on one course faculty member to grade all of the student videos. Although it may aid in grading consistency, the issue of time intensity for faculty has been cited as a challenge for video-assessment if grading is limited to one faculty member. ${ }^{13}$ One faculty grader resulted in a delay between student performance and faculty feedback. 


\section{LIMITATIONS AND FUTURE RESEARCH}

There were some limitations to this study. Using a rubric to score performance does not capture some of the benefits of video recording described in the literature related to the quality of the patient interaction, including non-verbal communication, the establishment of rapport, the reflection in action that occurs during patient management, behavioral habits, ease of movement, and flow of the session. The rubric was designed to evaluate whether a psychomotor skill was performed and if it was performed competently. However, the students reported on the perception survey that they were able to identify some of these issues from the video by identifying strengths and weaknesses that they were previously unaware of.

Another potential limitation is that the rubric used is not a validated tool. It was designed specifically to assess the outcomes outlined in the goals of this course by this particular course instructor, and there are currently no validated tools available that do so. If this tool continues to be used, it should be validated. Similarly, the perception survey answered the specific questions of interest to the faculty instructor. Future research could consider using a survey with open-ended questions that would generate rich qualitative data for analysis. This study could be replicated during additional practical examinations as the students' progress through the program to see if they have become more skilled in self-assessment later in the curriculum.

Additionally, All members of each group of three students picked up their scenarios at the same time, and were allowed to review them simultaneously prior to the first student's performance. Therefore, two of the 3 students within the group had more time to process the case and plan their approach to the session as they performed their roles as the standardized patient or videographer. This was a logistical problem that will have to be considered in future iterations of this format.

\section{CONCLUSION}

This research investigating the use of video recording to enhance student self-assessment during a practical examination demonstrated that PT students in their first year of a professional program are still dependent on faculty feedback for accurate assessment of performance. Despite low inter-rater and intra-rater reliability of scores, there are benefits to this format. Use of video recording during practical examinations may be useful to enhance self-reflection as students progress through the curriculum. It could also be a viable alternative for faculty to use if they do not have adequate support to administer a traditional practical assessment. This format has the potential to reduce student stress associated with assessment of clinical skills and was a positive experience that students recommended for future practical examinations.

\section{REFERENCES}

1. Gorman SL. Development and implementation of an objective structured clinical examination (OSCE) in neuromuscular physical therapy. J Phys Ther Educ Vol. 2010;24(3).

2. Panzarella KJ, Manyon AT. A model for integrated assessment of clinical competence. J Allied Health. 2007;36(3):157164.

3. Vendrely A. Student Assessment Methods in Physical Therapy Education: An Overview and Literature Review. J Phys Ther Educ. 2002;16(2):64-69.

4. $\quad$ Holey LA. A new way to assess practical physiotherapy skills. Med Teach. 1993;15(4):379.

5. Kurz JM, Mahoney K, Martin-Plank L, Lidicker J. Objective Structured Clinical Examination and Advanced Practice Nursing Students. J Prof Nurs. 2009;25(3):186-191. doi:10.1016/j.profnurs.2009.01.005

6. Howatson-Jones L. Reflective Practice in Nursing. 3rd ed. London: Learning Matters; 2016.

7. Pretorius L, Ford A. Reflection for Learning: Teaching Reflective Practice at the Beginning of University Study. Int J Teach Learn High Educ. 2016;28(2):241-253.

8. Seif GA, Brown D, Annan-Coultas D. Video-Recorded Simulated Patient Interactions: Can They Help Develop Clinical and Communication Skills in Today's Learning Environment? J Allied Health. 2013;42(2):37E-44E.

9. Musolino GM. Fostering Reflective Practice: Self-Assessment Abilities of Physical Therapy Students and Entry-Level Graduates. J Allied Health. 2006;35(1):30-42.

10. Kachingwe AF, Phillips B, Beling J. Videotaping Practical Examinations in Physical Therapist Education: Does It Foster Student Performance, Self-Assessment, Professionalism, and Improve Instructor Grading? J Phys Ther Educ. 2015;29(1):25-33.

11. Yoo MS, Yoo IY, Lee H. Nursing Students' Self-Evaluation Using a Video Recording of Foley Catheterization: Effects on Students' Competence, Communication Skills, and Learning Motivation. J Nurs Educ. 2010;49(7):402-405. doi:10.3928/01484834-20100331-03 
12. Mort JR, Hansen DJ. First-year Pharmacy Students' Self-Assessment of Communication Skills and the Impact of Video Review. Am J Pharm Educ. 2010;74(5). http://www.ncbi.nlm.nih.gov/pmc/articles/PMC2907843/. Accessed January 26, 2017.

13. Watts WE, Rush K, Wright M. Evaluating First-Year Nursing Students' Ability to Self-Assess Psychomotor Skills Using Videotape. Nurs Educ Perspect. 2009;30(4):214.

14. Lachman N, Pawlina W. Integrating professionalism in early medical education: The theory and application of reflective practice in the anatomy curriculum. Clin Anat. 19(5):456-460. doi:10.1002/ca.20344

15. Gopee N. Self assessment and the concept of the lifelong learning nurse. Br J Nurs. 2000;9(11):724-729. doi:10.12968/bjon.2000.9.11.6264

16. APTA Guide to professional conduct - Yahoo Search Results. https://search.yahoo.com/search?ei=utf8\&fr=tightropetb\&p=APTA+Guide+to+professional+conduct\&type=94641_032118. Accessed August 23, 2018.

17. Bryan RE, Krych AJ, Carmichael SW, Viggiano TR, Pawlina W. Assessing professionalism in early medical education: experience with peer evaluation and self-evaluation in the gross anatomy course. Ann Acad Med Singapore. 2005;34(8):486-491.

18. Lane JL, Gottlieb RP. Improving the Interviewing and Self-Assessment Skills of Medical Students: Is it Time to Readopt Videotaping as an Educational Tool? Ambul Pediatr. 2004;4(3):244-248. doi:10.1367/A03-122R1.1

19. Cruess RL, Cruess SR. Teaching professionalism: general principles. Med Teach. 2006;28(3):205-208. doi:10.1080/01421590600643653

20. Langendyk V. Not knowing that they do not know: self-assessment accuracy of third-year medical students. Med Educ. 2006;40(2):173-179.

21. Rees C. Students' and assessors' attitudes towards students' self-assessment of their personal and professional behaviours. Med Educ. 2005;39(1):30-39.

22. Nayer M. The assessment of clinical competency: an overview and preliminary report of Canadian physiotherapy programs. Physiother Can Physiothérapie Can. 1995;47(3):190-199.

23. Wessel J, Williams R, Finch E, Gémus M. Reliability and validity of an objective structured clinical examination for physical therapy students. J Allied Health. 2003;32(4):266-269.

24. Munoz LQ, O'Byrne C, Pugsley J, Austin Z. Reliability, validity, and generalizability of an objective structured clinical examination (OSCE) for assessment of entry-to-practice in pharmacy. Pharm Educ. 2005;5(1):33-43.

25. Nesbitt Cl, Phillips AW, Searle RF, Stansby G. Randomized trial to assess the effect of supervised and unsupervised video feedback on teaching practical skills. J Surg Educ. 2015;72(4):697-703.

26. Winters J, Hauck B, Riggs CJ, Clawson J, Collins J. Use of videotaping to assess competencies and course outcomes. J Nurs Educ Thorofare. 2003;42(10):472-476.

27. Franklin P. OSCEs as a means of assessment for the practice of nurse prescribing...Objective structured clinical examination. Nurse Prescr. 2005;3(1):14-23 8p.

28. Jensen R. Clinical reasoning during simulation: Comparison of student and faculty ratings. Nurse Educ Pract. 2013;13(1):23-28. doi:10.1016/j.nepr.2012.07.001

29. Allen R, Heard J, Savidge M, Bittergle J, Cantrell M, Huffmaster T. Surveying Students' Attitudes During the OSCE. Adv Health Sci Educ. 1998;3(3):197-206. doi:10.1023/A:1009796201104

30. Frank LM, Cassady SL. Health and wellness in entry-level physical therapy students: are measures of stress, anxiety, and academic performance related? Cardiopulm Phys Ther J Am Phys Ther Assoc Cardiopulm Sect. 2005;16(4):5-13.

\section{Appendix A. Gait competency self-assessment rubric (surveys \#1 and \#2)}

\section{Communication}

- Professional Dress

Hair orderly, clothes and white coat pressed, name tag displayed

- Introduction

Introduces self to patient using full name and school

Uses appropriate volume, speed, pitch

- Provides comprehensive summary of PT session Discusses fit of device and gait training session

- Explains purpose of assistive device and weight bearing status (if appropriate) Explains why assistive device is indicated

yes_no_

yes_no_

yes_no_

yes_no_ 


\begin{tabular}{|c|c|}
\hline $\begin{array}{l}\text { Explains weight bearing status in language that patient can understand (if } \\
\text { applicable)(Mark yes if you patient did not have a weight bearing restriction } \\
\text { and you did not need to address this) } \\
\text { Explains importance of adhering to weight bearing restrictions } \\
\text { (Mark yes if you did not need to address this) } \\
\text { Self-assessment } \\
\text { narrative. }\end{array}$ & $\begin{array}{l}\text { yes_no_ } \\
\text { yes_no_n_ } \\
\text { yes_no_n }\end{array}$ \\
\hline $\begin{array}{l}\text { Demonstration } \\
\text { - Set up of treatment environment } \\
\text { Space free of unnecessary clutter } \\
\text { Set up space to be conducive to gait training } \\
\text { - Assistive device fits SPT adequately for proper demonstration } \\
\text { Adjusts patient's assistive device or additional assistive device so fit is proper } \\
\text { for demonstration } \\
\text { - Correct performance of sit to stand and stand to sit } \\
\text { Considers patient's impairments and weight bearing status } \\
\text { Demonstrates scooting forward in chair } \\
\text { Emphasizes pushing from chair (with at least one UE) and not pulling on } \\
\text { device with UEs } \\
\text { Feet are in proper location for effective sit to stand (Demonstrates keeping the } \\
\text { foot with weight restrictions forward if patient has a weight bearing } \\
\text { restriction)shows } \\
\text { Shows what patient should do with trunk during sit to stand. (lean forward with } \\
\text { trunk or keep trunk erect with spinal or hip precautions) } \\
\text { Demonstrates proper gait pattern with use of assistive device } \\
\text { Demonstration is accurate for patient situation } \\
\text { Verbal instructions match gait demonstration } \\
\text { Demonstrates ambulating forward, turning, returning to chair } \\
\text { Self-assessment } \\
\text { narrative _ }\end{array}$ & $\begin{array}{l}\text { yes_no__ } \\
\text { yes_no__ } \\
\text { yes_no__ } \\
\text { yes_no__ } \\
\text { yes_no__ } \\
\text { yes_no__ } \\
\text { yes_no__ } \\
\text { yes_no__ } \\
\text { yes_no_n } \\
\text { yes_no_ } \\
\text { yes_no_ }\end{array}$ \\
\hline $\begin{array}{l}\text { Fitting Assistive device } \\
\text { - Performs proper gait belt application } \\
\text { Dons belt in appropriate location on patient's torso } \\
\text { Threads belt through teeth of belt first } \\
\text { Belt is not too loose or tight } \\
\text { Belt is not twisted } \\
\text { - Sit to stand transfer with effective guarding } \\
\text { SPT stands in correct location for guarding } \\
\text { Instructions to patient are clear and succinct } \\
\text { Patient's stability is maintained during fitting of device } \\
\text { Accurate fit of device } \\
\text { Performs "gestimate" for fit based on patient's height } \\
\text { Assistive device is placed in proper position in relation to patient (crutch and } \\
\text { cane tips are 4-6" forward and 2" lateral to patient's small toe, patient aligned } \\
\text { to rear legs of walker) for measuring height } \\
\text { Patient's elbows have } 20 \text {-300 flexion with shoulders relaxed or uses ulnar } \\
\text { styloid or greater trochanter as landmarks } \\
\text { Adequately guards patient during fitting procedure } \\
\text { Patient's weight bearing status maintained throughout fitting } \\
\text { (if appropriate)Mark yes if you did not need to be concerned with weigh } \\
\text { bearing status }\end{array}$ & $\begin{array}{l}\text { yes_no__n } \\
\text { yes_no__ } \\
\text { yes_no__ } \\
\text { yes_no_n } \\
\text { yes_no__ } \\
\text { yes_no__ } \\
\text { yes_no_n } \\
\text { yes_no_ }\end{array}$ \\
\hline
\end{tabular}




\begin{tabular}{|c|c|}
\hline $\begin{array}{l}\text { Self-assessment } \\
\text { narrative }\end{array}$ & \\
\hline $\begin{array}{l}\text { Gait training } \\
\text { - } \quad \text { Repeats effective instruction and guarding for sit to stand } \\
\text { - } \quad \text { Ensures patient performs proper gait pattern forward } \\
\text { - } \quad \text { Examines fit of assistive device and adjusts device if it appears too high or low } \\
\text { - } \text { during gait } \\
\text { - } \quad \text { Effective verbal cueing to perform or correct gait pattern } \\
\text { or tactile cues or physical assistance) mark yes if you did not need to be } \\
\text { - } \quad \text { SPTcerned with weight bearing status } \\
\text { - } \quad \text { SPT provides appropriate physical assistance } \\
\text { - Ensures patient performs proper stand to sit into w/c } \\
\\
\text { Self-assessment } \\
\text { narrative }\end{array}$ & $\begin{array}{l}\text { yes_no_- } \\
\text { yes_no__ } \\
\text { yes_no__ } \\
\text { yes_no__ } \\
\text { yes_no__ } \\
\text { yes_no_ } \\
\text { yes_no__ } \\
\text { yes_no__ } \\
\text { yes_no_ }\end{array}$ \\
\hline
\end{tabular}

\section{Appendix B Perception Survey}

Q1 Rate your stress level for this gait competency (practical)

Q2 Rate your stress level for the transfer practical that occurred earlier in the semester.

Q3 I was able to accurately assess my own performance on this gait practical before watching the video.

Q4 I was able to accurately assess my own performance on this gait practical after I watched the video recording of my performance.

Q5 I have identified areas of strength after watching the video recording that I did not recognize previously.

Q6 I have identified areas in need of improvement that I did not recognize previously.

Q7 I would like more testing experiences using this video format. 